The moderating role of narcissism on the reciprocal relationship between self-efficacy and performance

Beattie, Stuart; Dempsey, Chelsey; Roberts, Ross; Woodman, Tim; Cooke, Andrew

\title{
Sport, Exercise, and Performance Psychology
}

DOI:

$10.1037 /$ spy0000092

Published: 01/05/2017

Peer reviewed version

Cyswllt i'r cyhoeddiad / Link to publication

Dyfyniad o'r fersiwn a gyhoeddwyd / Citation for published version (APA):

Beattie, S., Dempsey, C., Roberts, R., Woodman, T., \& Cooke, A. (2017). The moderating role of narcissism on the reciprocal relationship between self-efficacy and performance. Sport,

Exercise, and Performance Psychology, 6(2), 199-214. https://doi.org/10.1037/spy0000092

Hawliau Cyffredinol / General rights

Copyright and moral rights for the publications made accessible in the public portal are retained by the authors and/or other copyright owners and it is a condition of accessing publications that users recognise and abide by the legal requirements associated with these rights. study or research.

- Users may download and print one copy of any publication from the public portal for the purpose of private

- You may not further distribute the material or use it for any profit-making activity or commercial gain

- You may freely distribute the URL identifying the publication in the public portal ?

Take down policy

If you believe that this document breaches copyright please contact us providing details, and we will remove access to the work immediately and investigate your claim. 
7

Running head: Narcissism, self-efficacy and performance

Manuscript accepted for publication in Sport, Exercise, and Performance

Psychology on 02/26/2017

The moderating role of narcissism on the reciprocal relationship between self-efficacy and performance

Stuart Beattie, Chelsey Dempsey, Ross Roberts, Tim Woodman and Andrew Cooke Institute for the Psychology of Elite Performance School of Sport, Health, and Exercise Sciences

Bangor University

UK

Correspondence concerning this article should be addressed to Dr Stuart Beattie, Institute for the Psychology of Elite Performance, Bangor University, George Building, Holyhead Road, Gwynedd, LL57 2PZ, United Kingdom. E-mail: s.j.beattie@bangor.ac.uk 


\section{Abstract}

2

3

4 Participants $(N=87)$ completed ten experimental trials on a driving simulator and we

5

6

7

$$
\text { We examined the moderating role of narcissism - a personality variable associated with }
$$
overconfidence - on the reciprocal relationship between self-efficacy and performance. recorded participants' performance and self-efficacy beliefs across trials. Hierarchical linear modelling demonstrated that performance had a positive relationship with self-efficacy (supporting the majority of self-efficacy research). However, narcissism moderated this relationship. Specifically, when narcissism was high, performance had no relationship with subsequent self-efficacy. Conversely, self-efficacy had a significant negative relationship with performance and narcissism did not moderate this relationship. A secondary purpose of the study was to examine the role of narcissism in the relationship between self-efficacy and effort, and between effort and performance. Narcissism significantly moderated the relationship between self-efficacy and self-reported effort, and between self-reported effort and performance.

Keywords: Self-efficacy, performance, narcissism, effort, positive, negative 
The moderating role of narcissism on the reciprocal relationship between self-efficacy and performance

Developed within the framework of social cognitive theory (Bandura, 1986), selfefficacy refers to "beliefs in one's capabilities to organise and execute courses of action required to produce given attainments" (Bandura, 1997, p. 3). Self-efficacy research has traditionally revealed that individuals with higher levels of self-efficacy enjoy cognitive and behavioural benefits compared to those with low levels of self-efficacy (Bandura, 1997). For example, higher levels of self-efficacy are associated with improved problem solving (Bouffard-Bouchard, 1990), increased adherence to exercise (Desharnais, Bouillon, \& Godin, 1986), increased sport performance (Moritz, Feltz, Fahrbach, \& Mack, 2000), and an increase in effort, exertion and persistence (Peak \& Cervone, 1989).

Despite a wealth of research that has demonstrated a positive relationship between self-efficacy and performance (e.g., Moritz et al., 2000; Stajkovic \& Luthans, 1998;

Woodman \& Hardy, 2003), recent theorizing suggests that one should interpret these findings with caution. For example, Vancouver, Thompson, and Williams (2001) stated that an overreliance on cross-sectional correlational research has concealed the true complexity of the self-efficacy/performance relationship and that research should examine such relationships within persons across time. Furthermore, Vancouver et al. (2001) stated that research often ignores the role of complacency within self-regulation theories, and increasing levels of self-efficacy may lead one to decrease the amount of resources allocated to a task, which in turn might harm performance. To this end, Vancouver et al. used control theory (Powers, 1973; 1991) to explain the reduction in resource allocation when self-efficacy is high. According to control theory, the discrepancy between a current and a desired state drives the motivation to act (i.e., to reduce goal discrepancy). However, control theory also proposes that high levels of self-efficacy might lead people to overestimate their perceptions 
1 of goal progress, which in turn might lead them to believe that they are closer to their goal

2 than they really are. Consequently, they reduce effort and performance suffers.

Vancouver et al. (2001; Vancouver, Thompson, Tischner, \& Putka, 2002) conducted a series of studies to examine the reciprocal relationship between self-efficacy and performance using the analytical task, Mastermind. Results revealed a significant positive relationship between past performance and subsequent self-efficacy; and a significant negative relationship between self-efficacy and subsequent performance. However, subsequent research testing Vancouver et al.'s predictions have revealed mixed results. For example, several studies have revealed significant negative relationships between self-efficacy and performance (e.g., Vancouver \& Kendall, 2006; Woodman, Akehurst, Hardy, \& Beattie, 2010; Yeo \& Neal, 2006); non-significant relationships (e.g., Beattie, Lief, Adamoulas \& Oliver, 2011; Richard, Diefendorff, \& Martin, 2006); and significant positive relationships (e.g., Beattie, Fakehy, \& Woodman, 2014; Seo \& Ilies, 2009).

One potential reason for the negative self-efficacy performance relationship is miscalibration (e.g., Beattie et al., 2011, 2014; Schmidt \& DeShon, 2010; Vancouver et al., 2001). Miscalibration is demonstrated when individuals display a bias (positive or negative) in their self-efficacy beliefs in comparison to their performance skills. For example, Beattie et al. (2011) found that participants repeatedly over-estimated their golf putting performance skills (positive miscalibration) by consistently overrating how many putts they thought they could achieve on an upcoming trial. Thus, the results of Beattie et al. add to the speculation that miscalibrated self-efficacy beliefs may lead to negative within-person self-efficacy and performance relationships (Vancouver et al., 2001; Vancouver \& Kendal, 2006). Research has often shown that self-views are fraught with error and contain a positive bias that reflects overconfidence (Dunning, Heath, \& Suls, 2004). Further, research also suggests that 
1 narcissistic individuals (Roberts, Woodman, \& Sedikides, 2017; Robins \& Beer, 2001) are

2 more prone to such positive self-bias effects.

Narcissism comes in two guises: grandiose and vulnerable. Grandiose narcissism

4 (examined within the current study) primarily reflects traits related to "grandiosity,

5 aggression, and dominance" (Miller et al., 2011, p. 1013). This is in contrast to vulnerable

6 narcissism (not examined within the current study), that is associated with "a defensive and

7 insecure grandiosity that obscures feelings of inadequacy" (Miller et al., 2011, p. 1013).

8 Grandiose narcissism is a personality disposition where individuals with high levels of

9 narcissism often display exceptional positive self-bias.

Narcissism could account for the negative self-efficacy and performance relationship in a number of ways. For example, previous research has shown that individuals scoring higher on narcissism tend to report overly positive self-bias through optimistic views regarding past performances, and consistently overrate their current performance (Robins \& Beer, 2001). Further, over a series of studies, Farwell and Wohlwend-Lloyd (1998) found that narcissism correlated with overly positive assessments of current performance (believing you performed better than you did), and self-enhancing attributions of past events. In addition, Campbell, Goodie, and Foster (2004) examined the relationship between narcissism, overconfidence, and decision making on a general knowledge-betting quiz. Campbell et al. found that narcissism positively related to overconfidence, and that overconfidence stemmed from an inflated sense of self and a perceived grand ability. Individuals with high levels of narcissism were also more willing to bet on their answers (due to greater overconfidence and a greater willingness to bet), and based their future performance predictions on performance expectations rather than past performance. That is, individuals scoring higher on narcissism partially base their ability estimates on factors not grounded in actual performance levels. Thus, we can predict that narcissism will moderate the robust finding that past performance 
1 has a strong and positive relationship with self-efficacy beliefs. That is, individuals who score

2 high in narcissism may demonstrate a weaker or no relationship between past performance

3 and self-efficacy.

There is also evidence to suggest that high levels of narcissism may contribute to the negative relationship between self-efficacy and subsequent performance for reasons mentioned above. Research demonstrates that individuals scoring higher on narcissism have a selective memory for self-flattering past events (Rhodewalt \& Eddings, 2002) and hold overly optimistic views of current performance and performance achievements (Farwell \& Wohlwend-Lloyd, 1998; Robins \& Beer, 2001), it is possible that individuals scoring higher on narcissism will report inflated levels of self-efficacy. Based on control theory's prediction that increasing levels of self-efficacy may induce complacency, and due to an inflated sense of self (Campbell et al., 2004), narcissism may partly explain the negative relationship often observed between self-efficacy and performance. For individuals with high levels of narcissism, self-efficacy may have no relationship or even a negative relationship with subsequent performance. Conversely, the performance of individuals with low levels of narcissism will likely benefit from their self-efficacy as their beliefs may be more grounded than that of individuals with high levels of narcissism.

A second purpose of the study was to examine what role narcissism played in the relationship between self-efficacy and effort, and between effort and performance. Research has demonstrated that the more efficacious an individual is, the more effort they invest in their given task (e.g., Krishnan, Netemeyer, \& Boles, 2002). Further, according to Vancouver et al. $(2001,2008)$ self-efficacy should have a positive relationship with goal choice and motivation. Specifically, high levels of self-efficacy may lead one to revise, set and pursue goals that are more difficult. However, once goals are accepted, high levels of self-efficacy may have a negative relationship to resource allocation. For example, Vancouver and Kendal 
1 (2006) examined the reciprocal relationship between self-efficacy, motivation (effort) and

2 exam performance over five repeated assessments on an undergraduate introductory course in industrial/organizational psychology. Results revealed a negative relationship between selfefficacy, performance and self-reported effort. That is, as self-efficacy for the students increased by a grade (e.g., B to B+), actual grade performance decreased by a quarter and self-reported study time decreased by 15 minutes.

Research on narcissism may also help to explain the above findings. For example, in order to promote a positive self-image, people with high levels of narcissism may also choose goals that are more difficult. However, research shows that individuals with higher levels of narcissism may engage more in self-handicapping activities (Feick \& Rhodewalt, 1997) if goal progress is not going to plan. Self-handicapping is an obstacle "created (or claimed) by the individual in anticipation of a failing performance" (Feick \& Rhodewalt, 1997, p. 147). Here, individuals with high levels of narcissism can protect their image in the event of failure. For example, high levels of narcissism may lead one to under report the amount of effort invested following a poor performance, which allows failure to be attributed to a lack of effort rather than to a lack of ability. Conversely, individuals might enhance their image following success because under-reporting the amount of effort invested will make a good performance appear more impressive. Research demonstrated that individuals with high levels of narcissism self-handicapped more than individuals with low levels of narcissism and that, self-handicapping was motivated by self-protection concerns such as to discount failure rather than to augment success (Rhodewalt, Tragakis, \& Finnerty, 2006). Finally, individuals with high levels of narcissism are generally overconfident (e.g., Campbell et al., 2004), tend to rely on external validation to feed their positive self-image, and seek to deny negative experiences and overemphasize positive experiences (Tracy, Cheng, Martens \& Robins, 
1 2011; Rhodewalt \& Morf, 1995). Thus, narcissism may moderate the relationships between

2 self-efficacy and self-report effort, and between self-report effort and performance.

One caveat to the above argument is that individuals with high levels of narcissism may only report that they are investing less effort but in reality, they may invest just as much effort as everyone else. Therefore, we supplemented our self-report measure of effort with a measure of heart rate variability (HRV). HRV is influenced by sympathetic and parasympathetic branches of the autonomic nervous system, with several studies associating an increase in mental effort and workload with decreases in HRV (e.g., Aasman, Mulder \& Mulder, 1987; Capa, Cleeremans, Bustin, Bouquet, \& Hensenne, 2011; De Rivecourt, Kuperus, Post, \& Mulder, 2008; Mulder, 1992). Importantly, the measurement of HRV should verify whether individuals with high levels of narcissism accurately report the amount of effort they claim to invest.

To summarise, the main aim of the present study was to examine the potential moderating role of narcissism on the reciprocal relationship between self-efficacy and performance. The first hypothesis was that narcissism would moderate the relationship between performance and self-efficacy. Specifically, individuals with low levels of narcissism will demonstrate a positive relationship between performance and subsequent selfefficacy, and individuals with high levels of narcissism will demonstrate a weak or no relationship between performance and subsequent self-efficacy (cf. Campbell et al., 2004).

The second hypothesis was that narcissism would moderate the relationship between self-efficacy and performance. Specifically, we predicted that individuals with high levels of narcissism would display a negative relationship between self-efficacy and performance, and individuals with low levels of narcissism would demonstrate a positive relationship between self-efficacy and performance (cf. Campbell et al., 2004; Farwell \& Wohlwend-Lloyd, 1998; Robins \& Beer, 2001). 
A second purpose of the study was to examine whether narcissism would moderate

2 the relationship between self-efficacy and effort, and between effort and performance.

3 Specifically, we hypothesized that there would be a negative relationship between self-

4 efficacy and effort for individuals with high levels of narcissism, and a positive relationship

5 between self-efficacy and effort for individuals with low levels of narcissism (cf. Rhodewalt

6 et al., 2006; Staijkovic \& Luthans, 1998). Finally, we hypothesized that narcissism would

7 moderate the relationship between effort and performance. Specifically, we hypothesized that

8 there would be no (or even perhaps a negative) relationship between effort and performance

9 for individuals with high levels of narcissism (e.g., Tracy et al., 2011), and a positive

10 relationship between effort and performance for individuals with low levels of narcissism.

\section{Method}

\section{Participants}

Eighty-seven participants $\left(M_{\text {age }}=22.45\right.$ years, $S D=3.51$ years; 59 men, 28 women $)$

volunteered to take part in the study. All participants had limited or no previous experience of driving simulator games (less than two hours per week). A University ethics board granted ethical approval and all participants provided informed consent before participating in the study.

\section{Apparatus}

Participants drove a custom designed racing circuit on Gran Turismo 5 for the PlayStation 3, viewed on a Hewlett Packard w2207h LCD - TFT 22 inch widescreen TV, using a driving simulator (Logitech G25 game seat, steering wheel, pedals, and gear stick). We custom made the track to ensure that no one had previous experience. Each participant used a Mazda MX5 car in automatic drive. The circuit was 2.89 miles $(4.65 \mathrm{~km})$ long (the 
1 longest straight section was 0.48 miles $(0.77 \mathrm{~km})$ and had seven corners of varying

2 difficulty ${ }^{1}$. No other cars were on the track.

We measured heart rate variability via an electrocardiogram using silver/silver

4 chloride electrodes (Blue Sensor SP, Ambu, Cambridgeshire, UK) positioned on the right

5 clavicle, left clavicle, and lower left rib. The electrocardiographic signal was digitized at

$61000 \mathrm{~Hz}$ with 16-bit resolution (PowerLab 16SP, AD Instruments, Dunedin, New Zealand),

7 and filtered $(0.3-50 \mathrm{~Hz})$ using LabChart7 software (AD Instruments).

\section{Procedure}

Pilot testing. In order to instil a sense of competition and motivation for the participants, we partly fabricated a leader board where participants could win cash prizes depending upon performance (see below). We piloted the study with five volunteers (who were not part of the final study). These five volunteers completed five trials of the racing circuit, with the fastest driver occupying the number one position (with a trial time of 251 seconds) on the leader board. The worst driver occupied position ten (with a trial time of 280 seconds). We then fabricated five further track times and inserted them between the top and bottom positions on the leader board. The leader board was on display to the participants at all times, where the names and times changed accordingly.

Main study. Participants attended one testing session. Upon arrival, we informed participants of the study procedure and obtained consent. Before the testing began, participants completed the NPI-16 (see below for measures). Next, we attached the three electrodes to the participant. They then sat in the driving simulator, made any necessary adjustments to the positions of the foot pedals and steering wheel to ensure they were comfortable. Participants received instructions of how to use the equipment, including the brake pedal, accelerator pedal, and reverse button.

\footnotetext{
${ }^{1}$ The circuit can be obtained from the $2^{\text {nd }}$ author.
} 
We introduced the participants to the leader board displayed on the wall above the TV screen. To motivate the participants, we then stated that the top ten fastest trials would win a cash prize ( $£ 50$ for first place, $£ 40$ for second place, $£ 30$ for third place, $£ 20$ for fourth place, and $£ 10$ for fifth to tenth place). We then briefed participants on how to use the mental effort and self-efficacy scales (see below), after which they were ready to commence driving.

Practice trials. In order for participants to familiarise themselves with the procedure and gain some experience of the equipment and track, participants completed three practice trials. We recorded heart rate as soon as the participant crossed the start line and paused it when participants crossed the finishing line. On completion of the first trial (and all subsequent trials), the game stopped whereupon the participants immediately completed the mental effort scale (RMSE; Zijlstra, 1993). After completing the RMSE, we told the participants their race time after which they completed the self-efficacy questionnaire. We reset the game and the whole cycle started again. The whole procedure in between trials lasted for about 1 minute.

Competitive trial. Before commencing with 10 competitive trials, we told the participants their best practice trial time. Participants used this time as a standard that they should improve upon over the coming competitive trials. The competitive trials procedure was identical to the practice trial procedure. In order for participants to judge their efficacy beliefs accurately, we provided them with a performance log of each trial time (combined time of two consecutive laps) up to that point (Beattie, Woodman, Fakehy, \& Dempsey, 2016). In other words, participants had access to feedback for each previous trial before they completed the self-efficacy questionnaire for the subsequent trial. The competitive trials followed the same procedure as the practice trials. Each trial lasted an average of 4 minutes and 39 seconds (ranging from 4 minutes and 17 seconds to 5 minutes and 9 seconds), during which the recording of HRV was continuous. Following the final trial, participants completed 
1 the mental effort scale, thanked for their time, and informed that we would contact them if

2 they had won a cash prize. The whole procedure (including practice and competitive trials)

$3 \quad$ lasted approx. 1 hour and 45 minutes.

4 Measures

5

Performance improvement. We recorded performance as the improvement (in seconds) from baseline to the current trial. For example, a baseline time of 300 seconds and a current trial time of 290 seconds would yield a performance improvement of 10 . We recorded performance improvement across trials 1-10.

Past performance. We recorded past performance in the same way as above and used it as a predictor variable in hypothesis 1 , and a control variable in hypotheses 2,3 , and 4 . Past performance is derived from performance improvement across trials 1-9 (i.e., trial 9 is the last past performance trial that can be used as past performance).

Self-efficacy. Following Beattie et al. (2011), we assessed self-efficacy magnitude by asking participants to answer yes or no to 20 statements: "I have the skills and resources to improve my baseline performance by one second", "I have the skills and resources to improve my baseline performance by two seconds", up to "I have the skills and resources to improve my baseline performance by 20 seconds." Participants were also given the opportunity to continue the scale if they wished (e.g., 21 seconds, 22 seconds, etc.). The total magnitude score was obtained by summing the number of 'yes' answers (e.g., if the participant answered 'yes' up to 15 seconds and "no" thereafter, his/her self-efficacy magnitude score was 15). Self-efficacy strength was recorded by asking participants to rate their degree of confidence in their ability to achieve that time $(0-100 \%)$ for each magnitude level to which participants had answered 'yes'. Total self-efficacy strength score for each trial 
1 was obtained by summing the strength percentages for every magnitude level that was answered with a ' $y e s^{2}$ '.

Self-report effort. We used Zijlstra's (1993) Rating Scale Mental Effort (RSME) to assess the level of mental effort exerted. Participants rated the effort that they invested by marking a cross on a continuous $150 \mathrm{~mm}$ line along which there was an anchor point every $10 \mathrm{~mm}$ indicating their effort from "no effort at all" $(0 \mathrm{~mm})$ to "extreme effort" $(150 \mathrm{~mm})$. We asked participants 'how much mental effort did you exert during the trial that you have just completed?' The scale has a test-retest reliability correlation coefficient of .78 (Zijlstra, 1993).

Heart rate variability. Heart rate variability (HRV) was calculated as the standard deviation of the R-wave to R-wave intervals (SDNN) of the electrocardiogram. SDNN is a time domain index of the spectral power in the $0.04 \mathrm{~Hz}$ to $0.15 \mathrm{~Hz}$ frequency band (Carrasco, Gaitan, Gonzalez, \& Yanez, 2001) and has been used as a psychophysiological marker of effort in previous research (e.g., Cooke et al., 2010; Mulder, 1992), where decreases in SDNN have been associated with increases in cognitive effort. We retained for analysis the mean heart rate variability for each trial.

Narcissism. We used the Narcissistic Personality Inventory-16 (NPI-16; Ames, Rose, \& Anderson, 2006) to assess narcissism. The NPI-16 is a shorter version of the NPI-40 (Raskin \& Terry, 1988) and comprises 16 pairs of items. For each pair of statements, participants are required to choose which statement (A or B) more closely matches their personality. For example, Item 1 asks participants to choose between (A) 'I really like to be the center of attention' or (B) 'It makes me uncomfortable to be the center of attention'. In this example, participants would score 1 point if they chose Statement A or no points if they

\footnotetext{
${ }^{2}$ The current data set demonstrated almost identical results when using self-efficacy magnitude or strength in the analysis. Thus, for ease of interpretation, we present self-efficacy magnitude results.
} 
1 chose Statement B. As such, the range of possible scores is 0-16. Jones and Figueredo (2013)

2 reported an alpha coefficient of .77 for the scale. Cronbach's alpha in the current study was .80. Following recommendations by Ames et al. (2006), we rescaled the mean narcissism scores to the level of the item by dividing participant totals by 16 . Specifically for the current study, we rescaled the mean NPI score of $3.68(S D=3.32$; range $0-16)$ to $M=0.23(S D=$ 0.21 ; range $0-1)$.

\section{Results}

We used Hierarchical Linear Modeling Version 7 (HLM; Raudenbush \& Bryk, 2002) to examine the within-person level effects. In this case, HLM allows us to examine whether there is a change in the relationships between the Level 1 variables (past performance, performance improvement, trial, self-efficacy, mental effort and SDNN) due to the Level 2 variable (narcissism). All Level 1 variables (past performance, performance improvement, trial, self-efficacy, mental effort and SDNN) are examined at a within-person level of analysis. For example, we are able to examine the relationship (e.g., positive or negative) between past performance and self-efficacy (or vice versa). We assessed all these variables across time (trials 1-10). When examining within-person relationship it is often noted that trends in the data (i.e., in the current study self-efficacy and performance significantly increase across time) could have a spurious effect on the results. Controlling for trial removes this possibility. Hence, trial is controlled for in all subsequent analyses.

The Level 2 variable (narcissism) is recorded once and is used as a between-person variable. In other words, we are able to examine whether the Level 1 within-person relationships differ as a result of narcissism. We used a full random intercept and slopes model. As data were nested within individuals across time (i.e., 10 competitive trials), we used group mean centering (data was centered on the individual) for all Level 1 variables (i.e., past performance, performance improvement, trial, self-efficacy, effort and SDNN). 
1 Conversely, the Level 2 variable (narcissism) was grand mean centered (data were centered

on the group mean). While checking for outliers, we removed 14 laps out of $870(1.45 \%$ of

the total data) where participants had large crashes. Table 1 displays the means, standard deviations, intraclass correlations ${ }^{3}$, and bivariate interclass correlations for the Level 1 variables (all scores represent the mean score across the 10 trials).

Considering the within-person set of analyses, self-efficacy magnitude significantly increased over time $\left(\mathrm{b}_{10}=.10, p=.05\right)$. Performance also significantly improved across time $\left(\mathrm{b}_{10}=.43, p<.01\right)$, indicating the change in the estimate of performance improvement over time was just under half of a second. We further examined whether narcissism (Level 2 variable) had a significant relationship (main effect) with any of our Level 1 outcome variables (i.e., past performance, performance improvement, self-efficacy, mental effort and SDNN). Narcissism did not significantly relate to any Level 1 variable: past performance $\left(b_{11}\right.$ $=-.67, p=.80)$, performance improvement $(\mathrm{b} 11=-.53, \mathrm{p}=.86)$, self-efficacy $\left(\mathrm{b}_{11}=.83, p=\right.$ $.83)$, mental effort $\left(\mathrm{b}_{11}=-23.39, p=.14\right)$, and $\operatorname{SDNN}\left(\mathrm{b}_{11}=-8.80, p=.53\right)$.

The first hypothesis predicted that narcissism would moderate the relationship between past performance and subsequent self-efficacy. Past performance had a significant and positive relationship with subsequent self-efficacy magnitude $\left(\mathrm{b}_{20}=.18, p<.001\right)$ whilst controlling for trial (supporting previous research e.g., Vancouver et al., 2001). Further, results supported the moderating effect of narcissism $\left(b_{21}=-.21, p=.08\right.$; see Figure $\left.1^{4}\right)$. Simple slopes analysis ${ }^{5}$ (e.g., Preacher, Curran, \& Bauer, 2006) revealed that the slope for

\footnotetext{
${ }^{3}$ To examine independence across participants, we calculated intraclass correlations (ICC) for all Level 1 variables that we used in the analysis (i.e., past performance, performance improvement, self-efficacy magnitude, SDNN and mental effort). The ICC, which represents the variance that was accounted for by the between-group effect (across Level 2 units, i.e., participants), ranged from .46 to .77, showing that between $46 \%$ and $77 \%$ of variance was associated with the between-group level. Multilevel modelling would be inappropriate if the ICC had been close to zero, because it would indicate that all participants behaved in a similar fashion.

${ }^{4}$ Following the recommendations of Snijders and Bosker (1999), cross-level interactions were accepted at $p<.1$ due to reductions in parameter reliability in multilevel modelling.

${ }^{5}$ Thank you to an anonymous review for suggesting these follow-up tests. The interested reader can perform these tests online at http://www.quantpsy.org/interact/hlm2.htm.
} 
1 high narcissism was not significant $(b=.09, p=.13)$ but the slope for low narcissism was

2 positive and significant $(\mathrm{b}=.17, p<.001)$. This indicates that there is a positive relationship

3 between past performance and subsequent self-efficacy for low narcissism only (see top tier

4 of Table 2).

5

6

Hypothesis 2 predicted that narcissism would moderate the relationship between selfefficacy and performance improvement. After controlling for trial, past performance, and self-report effort (see $2^{\text {nd }}$ tier of Table 2), the model revealed a significant negative relationship between self-efficacy magnitude and performance improvement $\left(\mathrm{b}_{40}=-.21, p=\right.$ .002). That is, as self-efficacy increased by 1 , driving performance worsened on average by a fifth of a second per trial. Narcissism did not moderate this relationship $\left(\mathrm{b}_{41}=.15, p=.64\right)$.

Hypothesis 3 predicted that narcissism would moderate the relationship between selfefficacy and self-reported mental effort. After controlling for trial and past performance, selfefficacy had no significant relationship with self-reported effort $\left(\mathrm{b}_{30}=-0.36, p=.07\right)$. In other words, as self-efficacy increased, self-reported effort did not significantly change. However, narcissism significantly moderated this relationship $\left(\mathrm{b}_{31}=-1.75, p=.075^{4}\right)$. Simple slopes analysis revealed that the high narcissism slope was significant and negative $(b=-$ $1.11, p=.03)$ and the slope for low narcissism was not significant $(b=-.37, p=.08)$; see Figure 2 and $3^{\text {rd }}$ tier of Table 2). This indicated that self-efficacy had a significant negative relationship with self-report effort when narcissism was high. When self-report effort was replaced with $\mathrm{HRV}\left(\mathrm{SDNN}^{6}\right)$, and controlling for trial and past performance, the relationship between self-efficacy and effort (SDNN) remained non-significant $\left(\mathrm{b}_{30}=.22, p=.26\right)$. Further, narcissism did not moderate the relationship between self-efficacy and HRV (SDNN; $\left.\mathrm{b}_{31}=-1.50, p=.22\right)\left(\right.$ see $4^{\text {th }}$ tier of Table 2$)$.

\footnotetext{
${ }^{6}$ Due to the availability of equipment, we were only able to obtain complete HRV data for 66 participants; hence analyses involving HRV used a sub-sample of 66 . Independent t-tests revealed no difference on any of the dependent variables between the HRV subsample and the main sample.
} 

report effort and performance improvement. After controlling for trial and past performance, self-reported effort had a significant positive relationship with performance improvement $\left(\mathrm{b}_{30}\right.$

$4=0.16, p<.001)$. Narcissism significantly moderated this relationship $\left(\mathrm{b}_{31}=-.18, p=.002\right.$ see $2^{\text {nd }}$ tier of Table 2). Simple slopes analysis revealed that the high narcissism $(b=.09, p=$ $.003)$ and low narcissism $(\mathrm{b}=.17, p<.001)$ slopes were positive and significant (Figure 3$)$. However, the slope for low narcissism was larger than high narcissism, indicating that selfreport effort had a significant positive relationship with performance improvement when narcissism was low but to a significantly lesser extent when narcissism was high. When replacing self-report effort with $\mathrm{HRV}$ (SDNN), the relationship indicated that increasing effort was again related to an increase in performance improvement $\left(\mathrm{b}_{30}=-.09, p<.001\right)$. However, narcissism did not moderate this relationship $\left(\mathrm{b}_{31}=-.02, p=.75\right)$ (see $2^{\text {nd }}$ tier of Table 2). reciprocal relationship between self-efficacy and performance. Results for the first hypothesis revealed that performance had a positive relationship with self-efficacy (better performance led to higher efficacy beliefs). This result supports the vast majority of within person selfefficacy research (Sitzman \& Yeo, 2013). Further, narcissism moderated the relationship between performance and self-efficacy in that, when narcissism was high, performance had no relationship with self-efficacy, but when narcissism was low, performance had a significant and positive relationship with self-efficacy. improvement, which has demonstrated positive, negative, and null relationships in the past (e.g., Beattie et al., 2016; Richard et al., 2006; Vancouver \& Kendall, 2006). Results found 
1 support for a control theory perspective (Powers, 1991) where self-efficacy had a negative

2 relationship with performance. However, there was no support for narcissism as a moderator

3 of this relationship.

Research tends to focus upon the second half of the reciprocal self-

5 efficacy/performance relationship (i.e., self-efficacy's relationship with performance) at the expense of the first half of the relationship (past performance effects upon subsequent selfefficacy) (Sitzman \& Yeo, 2013). This is perhaps not surprising, as psychologists tend to be more interested in performance effects. The finding that performance had no relationship with subsequent self-efficacy for individuals with high levels of narcissism is an interesting finding. For example, in their meta-analysis of reciprocal self-efficacy/performance relationships, Sitzman and Yeo (2013) found that performance had a strong and positive relationship with subsequent self-efficacy. In fact, this positive relationship is a robust finding in studies examining the reciprocal relationship between self-efficacy and performance. Results seem to suggest that individuals high in narcissism pay little regard to current performance standards and supports previous research that individuals with high levels of narcissism may, in part, base their future performance expectations on aspirations rather than actual past performances (e.g., Campbell et al., 2004). Regarding the second hypothesis, it is well documented that individuals with high levels of narcissism are overconfident (e.g., Campbell et al., 2004), and hold overly optimistic views of past performance accomplishments (Robins \& Beer, 2001). However, narcissism did not moderate the relationship between self-efficacy and performance. Perhaps one reason why narcissism did not moderate this relationship is that task engagement for individuals with high levels of narcissism is partly dependent on the opportunity for selfenhancement (e.g., Woodman et al., 2011). The current study did not set out to test such a moderator and used only a leader board to promote an opportunity for glory. Further, results 
1 of the first hypothesis show that individuals with high levels of narcissism did not rely on

2 past performances in order to judge subsequent efficacy beliefs. As narcissistic traits come to

3 the foray under higher opportunities for self-enhancement, it is possible that the negative

4 relationship between self-efficacy and performance for individuals with high levels of

5 narcissism would occur (i.e., they may be more likely to report inflated levels of self-

6 efficacy).

One final consideration that is worthy of note is that, despite providing participants

with all their past performance times on which they could base self-efficacy judgments upon, the more efficacious the individual was, the less performance improvement they made. This finding goes against current research where task feedback positively moderated the selfefficacy and performance relationship (e.g., Beattie et al., 2016). That is, when task feedback was low, self-efficacy had a negative relationship with performance. However, when task feedback was high, self-efficacy had a positive relationship with performance. The only difference between the current study and that of Beattie et al. (2016) is that the track changed and participants performed three extra laps in the experimental condition. It may have been that the track specifically designed for the current study was too easy and induced a sense of complacency or a performance ceiling effect. This would support Beattie at al.'s (2014) findings that task complexity moderates the relationship between self-efficacy and performance. That is, higher levels of performance are easier to obtain on easy tasks, therefore, subsequent performance improvements are harder to come by. This would limit any beneficial effect of self-efficacy upon subsequent performance (see also Beck \& Schmidt, 2012). However, this is a speculative comment, as we did not assess task complexity in the current study. A further reason is that the participants (as a group) did not choose to use the information available to them. 
A second purpose of the study was to examine what role narcissism had on the relationship between self-efficacy and effort, and between effort and performance improvement. We predicted that narcissism would moderate the relationship between selfefficacy and self-reported effort. In the present study, self-efficacy had no relationship with self-report effort (although the coefficient was negative and approached significance $p=.07$ ). Nevertheless, this finding fails to support previous research where self-efficacy had a significant negative relationship with exam study time (e.g., Vancouver \& Kendal, 2006). Further, narcissism moderated this relationship. That is, individuals with high levels of narcissism demonstrated a significant negative relationship between self-efficacy and selfreport effort, which would support a control theory perspective (Powers, 1991; Vancouver et al., 2001, 2002). Further, individuals with low levels of narcissism demonstrated a nonsignificant relationship between self-efficacy and self-report effort. Therefore, the current findings fail to support Social Cognitive Theory (Bandura, 1986) in that self-efficacy is positively related to effort. Finally, there was no relationship between self-efficacy and HRV and narcissism had no moderating effect.

Hypothesis 4 predicted that narcissism would moderate the relationship between selfreported effort and performance improvement. That is, if individuals with high levels of narcissism tend to under report effort exerted, then there should be no or a negative relationship between effort and performance for individuals with high levels of narcissism. As noted in the results, higher levels of self-reported effort were associated with better performance. Narcissism significantly moderated this relationship. That is, the relationship between self-reported effort and performance was significant and positive for individuals with low levels of narcissism. However, this relationship was also significant and positive for individuals with high levels of narcissism, albeit to a lesser extent. The significant interaction shows tentative support for our hypothesis that individuals high in narcissism under report 
1 effort exerted than individuals with low levels of narcissism. Similar to the self-efficacy and

2 effort hypothesis above, the interaction was present for self-reported effort but not HRV. Since self-report measures are susceptible to self-presentation bias (Rhodewalt \&

4 Fairfield, 1991), we measured HRV to give a multidimensional account of on-task effort to

5 supplement the self-report measure of effort. The moderating effect of narcissism for self-

6 reported effort but not HRV may be evidence that individuals with high levels of narcissism

7 fabricated their self-report effort responses. As mentioned, individuals higher in narcissism

8 are more likely to engage in self-handicapping than those low in narcissism (e.g., Rhodewalt

9 et al., 2006). Previous research has shown that individuals are willing to use self-

10 handicapping techniques (such as under reporting the amount of effort invested in a task) to protect themselves from failure, but are less willing to employ such techniques to enhance success (Rhodewalt, Morf, Hazlett \& Fairfield, 1991). Thus, if individuals with high levels of narcissism have performed lower than expected on a given trial, they have the opportunity post-trial to claim that they did not invest as much effort as they actually did. Therefore, they are able to attribute their poor performance to a lack of effort rather than a lack of ability. If we interpret HRV as a measure of effort, then the results demonstrate that although individuals with high levels of narcissism claim to invest less effort than individuals with low levels of narcissism, they are in fact investing the same amount of effort as low narcissists.

Although the above explanation makes theoretical sense, the results should be interpreted with caution for the following reasons. When mental effort is invested, a number of cardiovascular characteristics demonstrate changes, for example, heart rate and blood pressure increase, and a more regular heart beat (decreased HRV) is observed (Fairclough \& Mulder, 2012). Although a decrease in HRV has been associated with increased effort (e.g., Aasman et al., 1987; Capa et al., 2011; De Rivecourt et al., 2008; Mulder, 1992), a reduction in HRV is not perfectly correlated with a reduction in effort. For example, Veldhuizen van 
1 Zanten, De Boer, Harrison, Carroll, and Willemsen (2002) measured HRV at rest and during

2 a competitive remote control car-racing task, and demonstrated that the competitive trials had

3 lower heart rate variability than the less competitive trials. However, the decrease in HRV

4 was also associated with increases in self-report competitiveness, level of excitement, and

5 task difficulty. Further, Laborde, Furley, and Scnempp, (2015) found that resting HF-HRV

6 and not task related HF-HRV predicted performance on a working memory task. Thus, it is

7 somewhat difficult to confidently infer the HRV results of the current study as a pure

8 measure of effort, and further research is needed to conclude this interpretation.

There are some limitations to the current study. First, the opportunity for self-

enhancement may not have been enough to motivate those high in narcissism to invest effort.

Although there was an opportunity to win a cash prize and earn a place on the leader board, the results of the fastest trial times did not appear publically. Narcissists are motivated to invest more effort when their performance is going to be publically evaluated (e.g., Roberts, Callow, Hardy, \& Woodman., 2010; Roberts, Woodman, Hardy, Roberts, \& Wallace., 2013; Wallace \& Baumeister, 2002; Woodman et al., 2011). Thus, future research may wish to consider re-testing the potential moderating effect of narcissism on the relationship between self-efficacy and performance with a more pronounced opportunity for self-enhancement in a two-condition design (high and low opportunity for glory). Second, we concede that HRV is not a strong measure of on task mental effort, and we therefore encourage future research to explore additional psychophysiological measures of mental effort. For example, it is thought that changes in mental effort are more accurately measured via sympathetic nervous system mechanisms such as pre-ejection period and systolic blood pressure (Wright, 1996). Pupil dilation also indicates on task effort (Kahnemann, 1973; Alnaes, Sneve, Espeseth, Endestad, van de Pavert, Laeng, 2014) and absolute heart rate indicates an increase in on task effort in physical tasks (Greenlees, Graydon, \& Maynard, 1999). Thus, we recommend that future 
1 studies measuring cognitive effort via a psychophysiological approach, should avoid the self-

2 presentation bias in self-report measures by adopting some of these measures to shed further

3 light on this finding.

To conclude, results revealed that narcissism moderated the relationship between

5 performance and self-efficacy. In addition, narcissism moderated the relationships between

6 self-efficacy and effort, and between effort and performance improvement, but only when

7 using self-report effort, and not heart rate variability. Thus, we present tentative evidence that

8 individuals high in narcissism may have engaged in ego-protecting strategies, such as

9 attributing poor performance to a lack of effort rather than a lack of ability (Feick \&

10 Rhodewalt, 1997). Therefore, when one is working with an individual high in narcissism

11 (e.g., as a coach to an athlete or a superior in the workplace), it may be beneficial to encourage them to consider all objective feedback, in order to potentially improve selfregulation and discourage the attribution of sub-par performances to effort rather than ability. Indeed, if individuals disregard poor performance as a lack of effort rather than ability, there may be no motivation to invest resources in improving ability. We hope that future research will adopt a superior psychophysiological measure of mental effort, in order to solidify (or refute) the tentative conclusions around the moderating effect of narcissism upon the relationships between self-efficacy and effort, and between effort and performance. Finally, we recommend that future research examine these relationships in a different context in order to determine the generalizability and robustness of the results. 
Aasman, J., Mulder, G., \& Mulder, L. J. M. (1987). Operator effort and the measurement of heart-rate variability. Human Factors, 29, 161-170. doi:10.1177/001872088702900204

Alnæs, D., Sneve, M. H., Espeseth, T., Endestad, T., van de Pavert, S. H. P., Laeng, B. (2014). Pupil size signals mental effort deployed during multiple object tracking and predicts brain activity in the dorsal attention network and the locus coeruleus. Journal of Vision, 14 (4), 1-20.

Ames, D., Rose, P., \& Anderson, C. (2006). The NPI-16 as a short measure of narcissism. Journal of Research in Personality, 40, 440-450. doi:10.1016/j.jrp.2005.03.002.

Bandura, A. (1986). Social foundations of thought and action. Englewood Cliffs, NJ: Prentice Hall.

Bandura, A. (1997). Self-efficacy: The exercise of control. New York: Freeman.

Beattie, S., Woodman, T., Fakehy, M., Dempsey, C. (2016). The role of performance feedback on the self-efficacy performance relationship. Sport, Exercise, and Performance Psychology 5, 1-13. doi.org/10.1037/spy0000051

Beattie, S., Lief, D., Adamoulas, M., \& Oliver, E. (2011). Investigating the possible negative effects of self-efficacy upon golf putting performance. Psychology of Sport and Exercise, 12, 434-441. doi: 10.1016/j.psychsport.2011.02.004.

Beattie, S., Fakehy, M., \& Woodman, T. (2014). Examining the moderating effects of time on task and task complexity on the within person self-efficacy and performance relationship. Psychology of Sport and Exercise, 6, 605-610. doi:10.1016/j.psychsport.2014.06.007.

Beck, W. A., \& Schmidt, A. M. (2012). Taken out of context? Cross level effects of between-person self-efficacy and difficulty on the within-person relationship of 
self-efficacy with resource allocation and performance. Organizational Behavior and Human Decision Processes, 119, 195-208. http://dx.doi.org/10.1016/j.obhdp. 2012.06.009.

Bouffard-Bouchard, T. (1990). Influence of self-efficacy on performance in a cognitive task. Journal of Social Psychology, 130, 353-363. doi: 10.1080/00224545.1990.9924591.

Campbell, K., Goodie, A., \& Foster, J. (2004). Narcissism, confidence, and risk attitude. Journal of Behavioral Decision Making, 17, 297-311. doi: 10.1002/bdm.475.

Capa, R. L., Cleeremans, A., Bustin, G. M., Bouquet, C. A., \& Hansenne, M. (2011). Effects of subliminal priming on nonconscious goal pursuit and effort-related cardiovascular response. Social Cognition, 29, 430-444.

Carrasco, S., Gaitan, M., Gonzalez, R., Yanez, O. (2001). Correlation among Poincaré plot indexes and time and frequency domain measures of heart rate variability. Journal of medical engineering and technology, 25, 240-248. doi:10.1080/03091900110086651

Cooke, A., Kavussanu, M., McIntyre, D., \& Ring, C. (2010). Psychological, muscular and kinematic factors mediate performance under pressure. Psychophysiology, 47, 11091118. doi: $10.1111 /$ j.1469-8986.2010.01021.x

Desharnais, R., Bouillon, J., \& Godin, G. (1986). Self-efficacy and outcome expectations as determinants of exercise adherence. Psychological Reports, 59, 1155-1159. doi: 10.2466/pr0.1986.59.3.1155.

De Rivecourt, M., Kuperus, M. N., Post, W. J., \& Mulder, L. J. M. (2008). Cardiovascular and eye activity measures as indices for momentary changes in mental effort during simulated flight. Ergonomics, 51, 1295-1319.

Dunning, D., Heath, C., \& Suls, J. (2014). Flawed Self-assessment. Implications for Health, Education, and the Workplace. Psychological Science in the public interest, 5, 69106. 
1 Ettema, J. H., \& Zielhuis, R. L. (1971). Physiological parameters of mental load.

2 Ergonomics, 14, 137-144.

Fairclough, S. H., \& Mulder, L. J. M. (2011). Psychophysiological processes of mental effort investment. How motivation affects cardiovascular response: Mechanisms and applications, 61-76.

Farwell, L., \& Wohlwend-Lloyd, R. (1998). Narcissistic processes: Optimistic expectations, favourable self-evaluations, and self-enhancing attributions. Journal of Personality, 66, 65-83. doi:10.1006/jrpe.2000.2282.

Feick, D. L., \& Rhodewalt, F. (1997). The double-edged sword of self-handicapping: Discounting, augmentation, and the protection and enhancement of selfesteem. Motivation and Emotion, 21(2), 147-163.

Greenlees, I. A., Graydon, J. K., \& Maynard, I. W. (1999). The impact of collective efficacy beliefs on effort and persistence in a group task. Journal of Sport Sciences, 17, 151158. doi.org/10.1080/026404199366253

Jones, D., \& Figueredo, A. (2013). The core of darkness: Uncovering the heart of the dark triad. European Journal of Personality, 6, 521-531. doi: 10.1002/per.1893.

Kahnemann, D. (1973). Attention and effort. Englewood Cliffs, NJ: Prentice Hall.

Kernis, M. H., \& Sun, C. (1994). Narcissism and reactions to interpersonal feedback. Journal of Research in Personality, 28, 4-13. doi:10.1006/jrpe.1994.1002.

Krishnan, B. C., Netemeyer, R. G., \& Boles, J. S. (2002). Self-efficacy, competitiveness, and effort as antecedents of salesperson performance. Journal of Personal Selling and Sales Management, 22, 285-295.

Laborde, S., Furley, P., \& Schempp. C. (2015). The relationship between working memory, reinvestment, and heart rate variability. Physiology \& Behavior, 139, 430-436. doi.org/10.1016/j.physbeh.2014.11.036 
1 Morf, C., \& Rhodewalt, F. (2001). Unraveling the paradoxes of Narcissism: A dynamic selfregulatory processing model. Psychological Inquiry: An International Journal for the Advancement of Psychological Theory, 12, 177-196. doi:10.1207/S15327965PLI1204_1.

Moritz, S., Feltz, D., Fahrbach, K., \& Mack, D. (2000). The relation of self-efficacy measures to sport performance: A meta-analytic review. Research Quarterly for Exercise and Sport, 71, 280-294. doi: 10.1080/02701367.2000.10608908.

Mulder, L. J. M. (1992). Measurement and analysis methods of heart rate and respiration for use in applied environments. Biological Psychology, 34, 205-236. doi:10.1016/03010511(92)90016-N

Peake, P. K., \& Cervone, D. (1989). Sequence anchoring and self-efficacy: primacy effects in the consideration of possibilities. Social Cognition, 7, 31-50.

Powers, W. T. (1973). Behavior: The control of perception. New York: Hawthorne.

Powers, W. T. (1991). Commentary on Bandura's "human agency." American Psychologist, 46, 151-153. doi: 10.1037/0003-066X.46.2.151.b.

Preacher, K. J., Curran, P. J., \& Bauer, D. J. (2006). Computational tools for probing interaction effects in multiple linear regression, multilevel modeling, and latent curve analysis. Journal of Educational and Behavioral Statistics, 31, 437-448.

Raudenbush S. W, Bryk A. S. (2002). Hierarchical linear models: Applications and data analysis methods. Thousand Oaks, CA: Sage.

Raskin, R., \& Terry, H. (1988). A principle-components analysis of the Narcissistic Personality Inventory and further evidence of its construct validity. Journal of Personality and Social Psychology, 54, 890-902. doi: 10.1037/0022-3514.54.5.890. 
1 Rhodewalt, F., \& Eddings, S. K. (2002). Narcissus reflects: Memory distortion in response to ego-relevant feedback among high- and low-narcissistic men. Journal of Research in Personality, 36, 97-116. doi:10.1006/jrpe.2002.2342.

Rhodewalt, F., \& Fairfield, M. (1991). Claimed self-handicaps and the self-handicapper: The relation of reduction in intended effort to performance. Journal of Research in Personality, 25 (4), 402-417. doi:10.1016/0092-6566(91)90030-T

Rhodewalt, F., \& Morf, C. (1995). Self and interpersonal correlates of the narcissistic personality inventory: A review and new findings. Journal of Research in Personality, 29, 1-23. doi: 10.1006/jrpe.1995.1001.

Rhodewalt, F., Morf, C, Hazlett, S., \& Fairfield, M. (1991). Self-handicapping: The role of discounting and augmentation in the preservation of self-esteem. Journal of Personality and Social Psychology, 61, 121-131. doi: 10.1037/0022-3514.61.1.122.

Rhodewalt, F., Tragakis, M. W., \& Finnerty, J. (2006). Narcissism and self-handicapping: Linking self-aggrandizement to behaviour. Journal of Research in Personality, 40, 573-597. doi:10.1016/j.jrp.2005.05.001

Richard, E., Diefendorff, J., \& Martin, J. (2006). Revisiting the within-person self-efficacy and performance relations. Human Performance, 19, 67-87. doi:10.1207/s15327043hup1901_4.

Roberts, R., Callow, N., Hardy, L., \& Woodman, T. (2010). Interactive effects of different visual imagery perspectives and narcissism on motor performance. Journal of Sport \& Exercise Psychology, 32, 499-517.

Roberts, R., Woodman, T., Hardy, L., Roberts, L., \& Wallace, H. M. (2013). Psychological skills do not always help performance: The moderating role of narcissism. Journal of Applied Sport Psychology, 25, 316-325. doi:10.1080/10413200.2012.731472 
1 Roberts, R., Woodman, T., Lofthouse, S., \& Williams, L. (2014). Not all players are equally motivated: The role of narcissism. European Journal of Sport Science, 15, 536-542, doi: 10.1080/17461391.2014.987324

Roberts, R., Woodman, T., \& Sedikides, C. (2017). Pass Me the Ball: Narcissism in Performance Settings. International Review of Sport \& Exercise Psychology (in press) doi:10.1080/1750984X.2017.1290815.

Robins, R., \& Beer, J. (2001). Positive illusions about the self: Short-term benefits and longterm costs. Journal of Personality and Social Psychology, 80, 354-352. doi: 10.1037/0022-3514.80.2.340.

Schmidt, A., \& DeShon, R. (2010). The moderating effects of performance ambiguity on the relationship between self-efficacy and performance. Journal of Applied Psychology, 95, 572-581. doi:10.1037/a0018289.

Seo, M., \& Ilies, R. (2009). The role of self-efficacy, goal, and affect in dynamic motivation self-regulation. Organizational Behavior and Human Decision Processes, 109, 120 133. doi:10.1016/j.obhdp.2009.03.001.

Sitzmann, T., \& Yeo, G. (2013). A meta-analytic investigation of the within-person selfefficacy domain: Is self-efficacy a product of past performance or a driver of future performance. Personnel Psychology, 66, 531-568. doi: 10.1111/peps.12035.

Snijders, T., \& Bosker, R. (1999). Multilevel modeling: An introduction to basic and advanced multilevel modeling. London, England. Sage.

Stajkovic, A., \& Luthans, F. (1998). Self-efficacy and work-related performance: A metaanalysis. Psychological Bulletin, 124, 240-261. doi: 10.1037/0033-2909.124.2.240.

Tracy, J. L., Cheng, J. T., Martens, J. P. and Robins, R. W. (2011) The Emotional Dynamics of Narcissism, in The Handbook of Narcissism and Narcissistic Personality Disorder: Theoretical Approaches, Empirical Findings, and Treatments (eds W. K. Campbell 
and J. D. Miller), John Wiley \& Sons, Inc., Hoboken, New Jersey. doi: $10.1002 / 9781118093108 . \operatorname{ch} 29$

Vancouver, J. B. (2012). Rhetorical reckoning: a response to Bandura. Journal of Management, 38, 465-474. http://dx.doi.org/10.1177/0149206311435951.

Vancouver, J., \& Kendall, L. (2006). When self-efficacy negatively relates to motivation and performance in a learning context. Journal of Applied Psychology, 91, 1146-1153. doi:10.1037/0021-9010.91.5.1146

Vancouver, J. B., Thompson, C. M., Tischner, E. C., \& Putka, D. J. (2002). Two studies examining the negative effect of self-efficacy on performance. Journal of Applied Psychology, 87, 506-516. doi:10.1037/0021-9010.87.3.506.

Vancouver, J. B., Thompson, C. M., \& Williams, A. A. (2001). The changing signs in the relationships between self-efficacy, personal goals, and performance. Journal of Applied Psychology, 86, 605-620. doi:10.1037/0021-9010.86.4.605.

Veldhuizen, van Zanten, J. J. C. S., De Boer, D., Harrison, L. K., Ring, C., Carroll, D., Willemsen, G., et al. (2002). Competitiveness and hemodynamic reactions to competition. Psychophysiology, 39, 759-766.

Wallace, H., \& Baumeister, R. (2002). The performance of narcissists rises and falls with perceived opportunity for glory. Journal of Personality and Social Psychology, 82, 819-834. doi: 10.1037/0022-3514.82.5.819.

Wilson, T. D. (2002). Strangers to ourselves: Discovering the adaptive unconscious. Cambridge, MA: Harvard University Press.

Woodman, T., Akehurst, S., \& Hardy, L., \& Beattie, S. (2010). Self-confidence and performance: A little self-doubt helps. Psychology of Sport \& Exercise, 11, 467-470. doi: 10.1016/j.psychsport.2010.05.009. 
1 Woodman, T., \& Hardy, L. (2003). The relative impact of cognitive anxiety and self-

2

3

4

5

6

7

8

9 confidence upon sport performance: a meta-analysis. Journal of Sports Sciences, 21, 443-457.

Woodman, T., Roberts, R., Hardy, L., Callow, N., \& Rogers, C. H. (2011). There is an "I" in TEAM: narcissism and social loafing. Research Quarterly for Exercise \& Sport, 82, 285-290. doi: 10.1080/02701367.2011.10599756.

Wright, R. A. (1996). Brehm's theory of motivation as a model effort and cardiovascular response. In P.M. Gollwitzer \& J. A. Bargh (Eds.), The psychology of action: Linking cognition and motivation to behaviour (pp. 424-453). New York, NY: Guilford Press.

Yeo, G., \& Neal, A. (2006). An examination of the dynamic relationship between selfefficacy and performance across levels of analysis and levels of specificity. Journal of Applied Psychology, 91, 1088-1101. doi:10.1037/0021-9010.91.5.1088.

Zijlstra, F. R. H. (1993). Efficiency in work behaviour: A design approach for modern tools. Delft University Press. 
1 Table 1

2 Means, standard deviations, intraclass correlations (ICC), and bivariate correlations of all Level-1 variables and narcissism.

\begin{tabular}{|c|c|c|c|c|c|c|c|c|}
\hline Variable & $\operatorname{Mean}^{7}(\mathrm{SD})$ & $\begin{array}{l}\text { Actual } \\
\text { Range }\end{array}$ & ICC & 1 & 3 & 4 & 5 & 6 \\
\hline 1. Past performance & $2.92(7.13)$ & $-19-24$ & .46 & & & & & \\
\hline 2. Performance improvement & $.73(6.34)$ & $-24-21$ & .51 & $.63 * *$ & - & & & \\
\hline 3. Self-efficacy magnitude & $7.77(5.74)$ & $0-27$ & .74 & $.51^{* *}$ & $.40 * *$ & - & & \\
\hline 4. SDNN & $64.37(25.79)$ & $20.15-207$ & .69 & -.02 & $.13^{*}$ & $-.10^{*}$ & - & \\
\hline 5. Mental Effort & $81.88(27.86)$ & $5-150$ & .77 & $.13^{*}$ & $.24 * *$ & .05 & $-.20 * *$ & - \\
\hline 6. Narcissism & $0.23(0.21)$ & $0-.81$ & - & -.02 & -.02 & .04 & -.07 & $-.12 *$ \\
\hline
\end{tabular}

$3 \quad$ Notes: $* p<.05 ; * * p<.01$. 
Main and moderating effects between Level-1 and Level-2 variables.

\begin{tabular}{|c|c|c|c|c|c|}
\hline & $\begin{array}{c}\mathrm{b}^{8} \\
\text { Unstand }\end{array}$ & $\begin{array}{c}\mathrm{SE} \\
\text { (robust) }\end{array}$ & $\begin{array}{c}\beta \\
\text { STND }\end{array}$ & $\begin{array}{c}\mathrm{SE} \\
\text { (robust) }\end{array}$ & $\begin{array}{c}\text { Total } \\
\text { Variance \% }\end{array}$ \\
\hline \multicolumn{6}{|l|}{ DV $=$ Self-efficacy } \\
\hline \multicolumn{6}{|l|}{ Level 1} \\
\hline Trial number & .10 & $.05^{*}$ & .00 & .00 & 46.94 \\
\hline Past performance & .18 & $.02 * *$ & .18 & $.00 *$ & 62.10 \\
\hline \multicolumn{6}{|l|}{ Level 2 Interaction } \\
\hline Narcissism $\times$ Past performance & -.21 & $.12 \mathrm{a}$ & -.05 & $.03 \mathrm{a}$ & 62.17 \\
\hline \multicolumn{6}{|l|}{ DV $=$ Performance improvement } \\
\hline \multicolumn{6}{|l|}{ Level 1} \\
\hline Trial number & .43 & $.08 * *$ & .06 & $.01 * *$ & 22.02 \\
\hline Past performance & .03 & .03 & .03 & .03 & 22.68 \\
\hline Self-efficacy & -.21 & $.06 * *$ & -.16 & $.04 * *$ & 41.61 \\
\hline Self-report mental effort & .16 & $.01 * *$ & .59 & $.05 * *$ & 40.99 \\
\hline SDNN & -.09 & $.02 * *$ & -.32 & $.05 * *$ & 30.50 \\
\hline \multicolumn{6}{|l|}{ Level 2 Interaction } \\
\hline Narcissism $\times$ Self-efficacy & .15 & .31 & -.02 & .05 & 41.62 \\
\hline Narcissism $\times$ Self-report mental & & & & & \\
\hline effort & -.18 & $.06 * *$ & -.10 & $.04 *$ & 41.48 \\
\hline Narcissism $\times$ SDNN & -.02 & .08 & -.01 & .05 & 30.61 \\
\hline \multicolumn{6}{|l|}{ DV = Self-report mental effort } \\
\hline \multicolumn{6}{|l|}{ Level 1} \\
\hline Trial number & .78 & $.25^{* *}$ & .02 & $.00 * *$ & 20.91 \\
\hline Past performance & .01 & .09 & .01 & .02 & 20.96 \\
\hline Self-efficacy & -.36 & .20 & -.07 & .04 & 21.78 \\
\hline \multicolumn{6}{|l|}{ Level 2 Interaction } \\
\hline Narcissism $\times$ Self-efficacy & -1.75 & $.97 \mathrm{a}$ & -.07 & $.04 \mathrm{a}$ & 21.91 \\
\hline \multicolumn{6}{|l|}{$\mathrm{DV}=\mathrm{SDNN}$} \\
\hline \multicolumn{6}{|l|}{ Level 1} \\
\hline Trial number & .84 & $.27 * *$ & .03 & $.01 * *$ & 12.97 \\
\hline Past performance & .00 & .12 & .00 & .03 & 13.57 \\
\hline Self-efficacy & .22 & .19 & .05 & .04 & 13.91 \\
\hline \multicolumn{6}{|l|}{ Level 2 Interaction } \\
\hline Narcissism $\times$ Self-efficacy & -1.50 & 1.22 & -.07 & .05 & 13.87 \\
\hline
\end{tabular}
a $p<.1 ; * p<.05 ; * * p<.01$

$4 \quad$ Unstand $=$ Unstandardized. STND $=$ Standardised. DV $=$ Dependent variable. Level 2

5 variable is the moderator variable narcissism. Total Variance: Total variance accounted for is 6 when a Level 1 predictor variable is added to the model. For example, in the top tier, trial 7 number explains $46.94 \%$ of the variance in self-efficacy. The total variance that trial number 8 and past performance accounts for is $62.10 \%$. Therefore, the variance that past performance 9 explains above that of Trial number is $15.16 \%$.

10 As narcissism was unrelated to any of the outcome variables, it is not reported in this Table.

\footnotetext{
${ }^{8} \mathrm{~b}=$ multilevel regression coefficients, which are sometimes referred to as gamma $(\gamma)$ in multilevel modelling
} 
1 Figure 1. The moderating effect of narcissism on the relationship between past performance 2 and subsequent self-efficacy ${ }^{9}$.

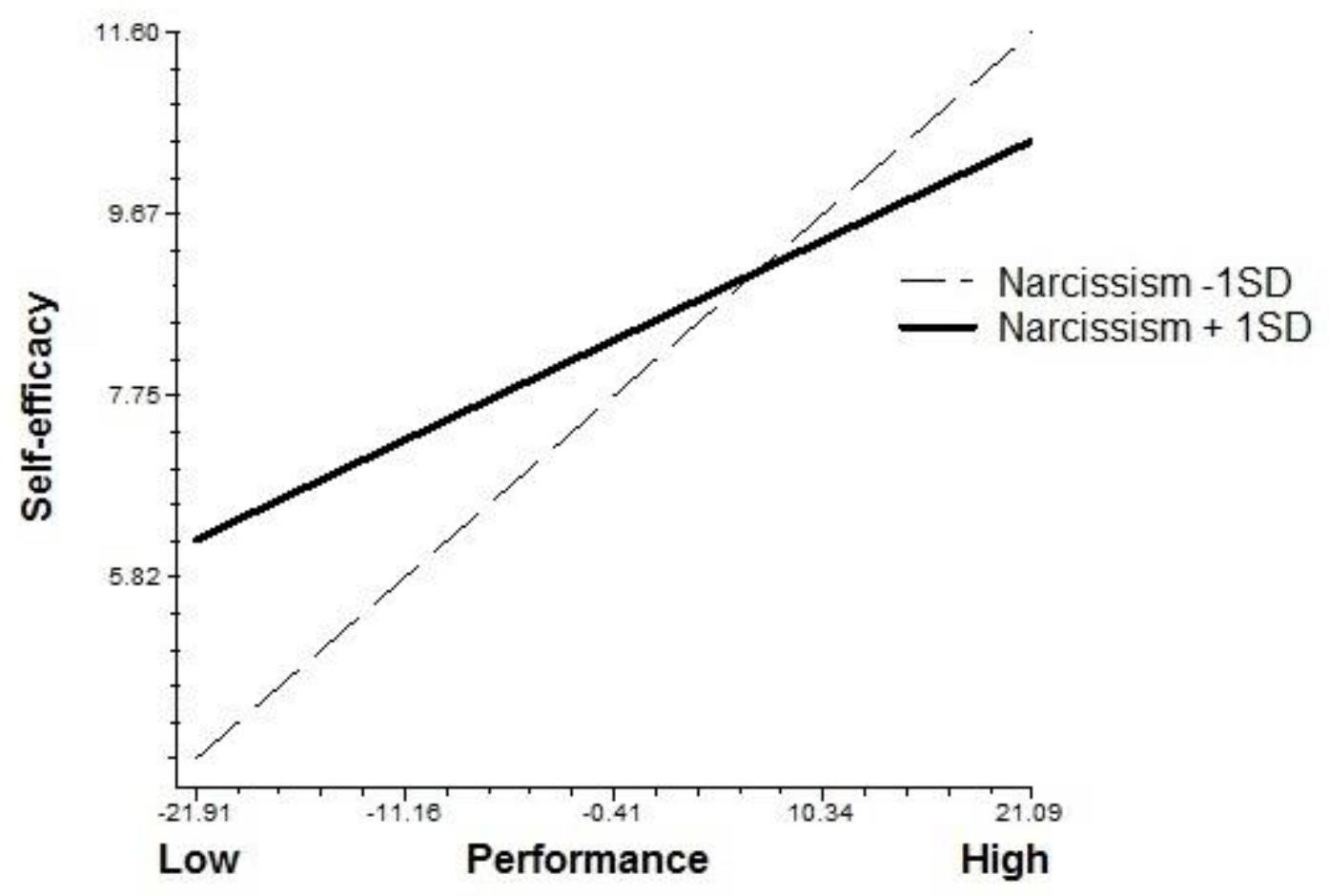

\footnotetext{
${ }^{9}$ When plotting the interactions in Figures 1, 2, and 3, we used the full range of scores of the independent variable and plotted the moderator (narcissism) at $1 S D$ above the mean (i.e., $.23+.21=.44$ ) and $1 S D$ below the mean (i.e., $.23-.21=.02$ ).
} 
1 Figure 2. The moderating effect of narcissism on the relationship between self-efficacy and 2 self-reported effort.

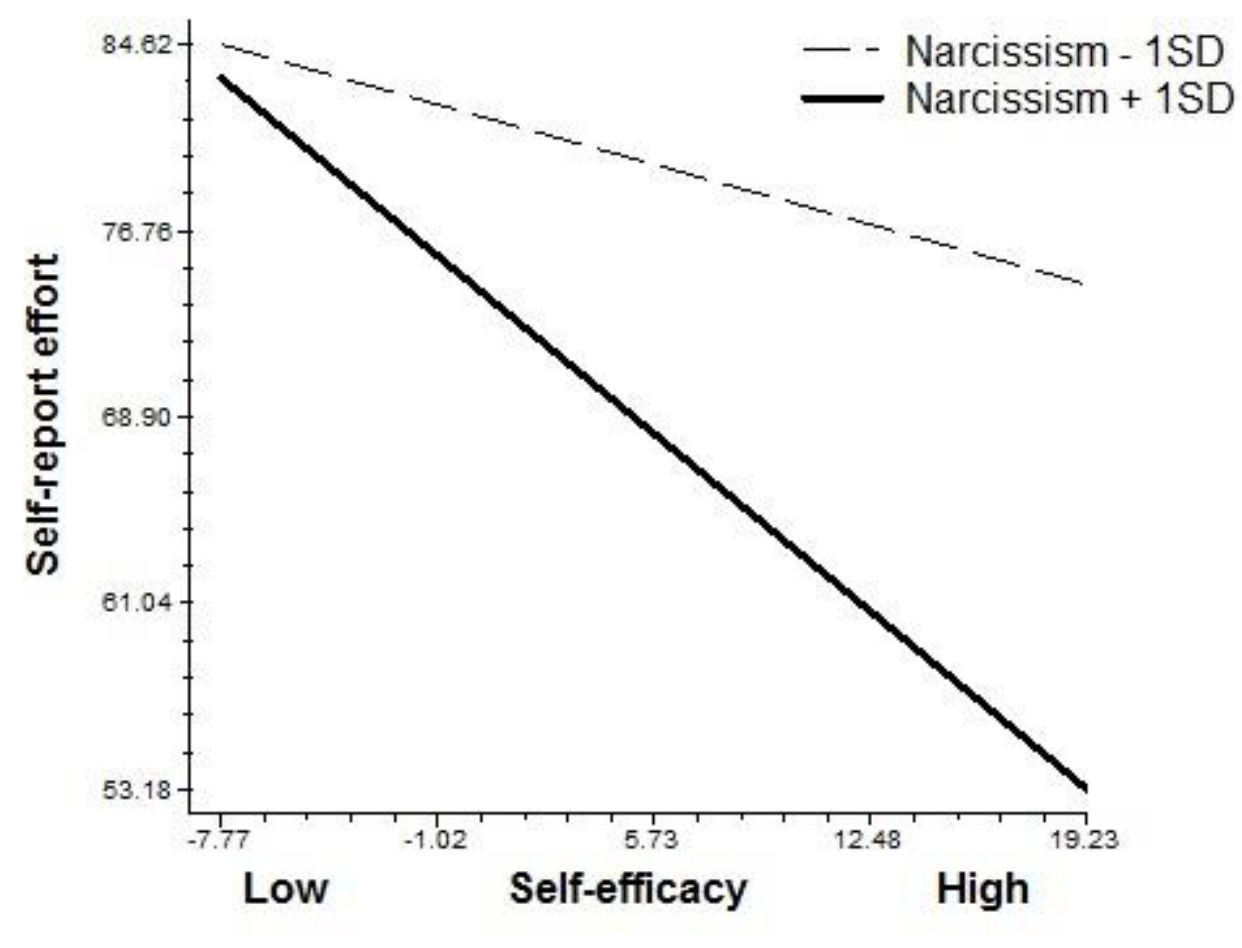

3 
1 Figure 3. The moderating effect of narcissism on the relationship between self-report effort 2 and performance improvement.

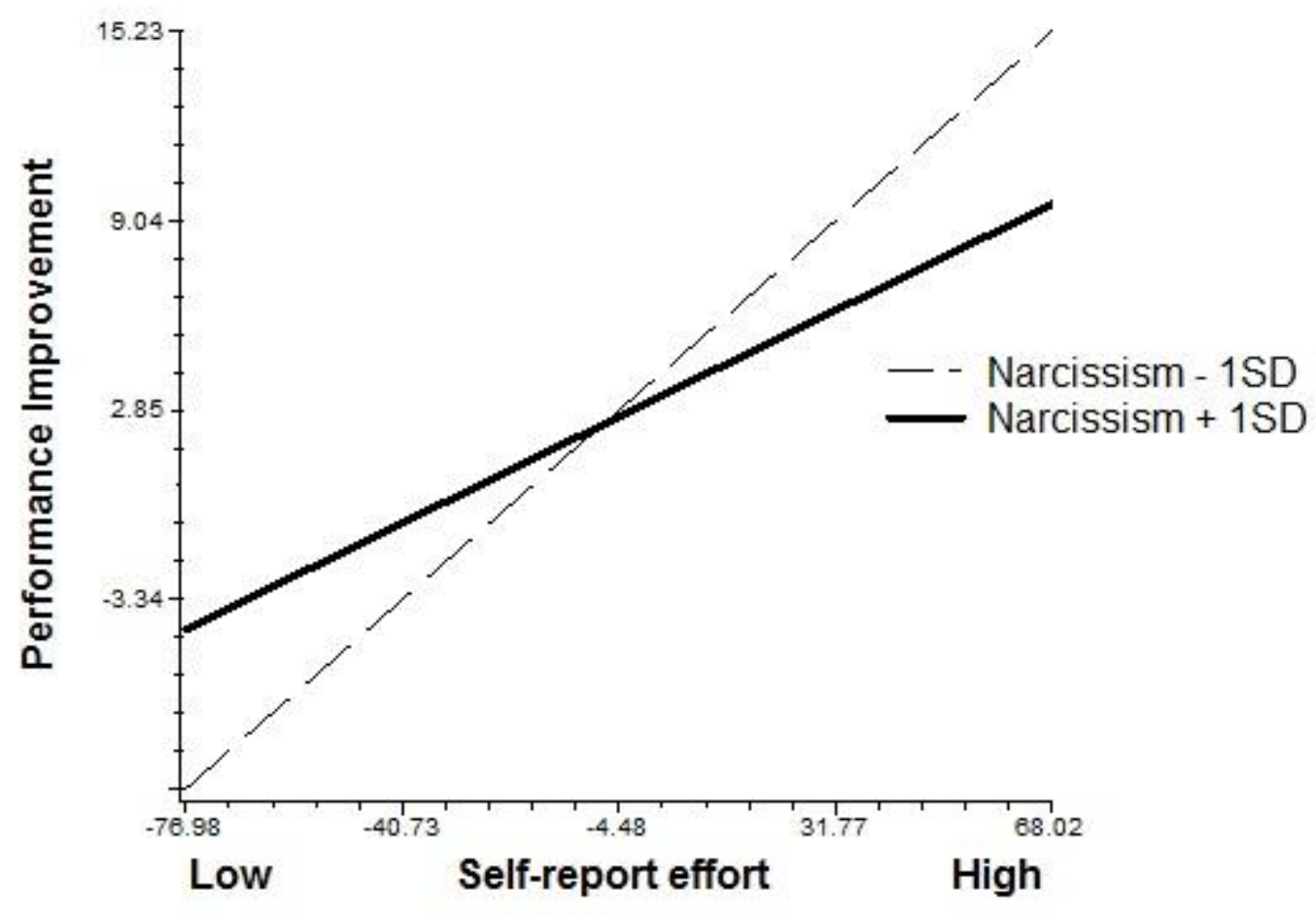

